RESEARCH ARTICLE

\title{
Blockchain Technology as a Competitive Advantage for Higher Education Institutions in the Philippines
}

Marita T. Salandanan, DBA

Emilio Aguinaldo College - Cavite, Philippines

\begin{abstract}
This research explores blockchain as a competitive advantage (CA) for higher education institutions (HEIs) in the Philippines. The respondents' awareness of the relevance of blockchain use was also tested. The researcher aims to verify if blockchain is a foundational technology to be implemented in academe. Theoretical framework was formulated based on the knowledge procurement cycle and distributed learning ledger. The researcher proposes that conceptual framework, centered on blockchain (Ethereum), will enhance recordkeeping in education. Frequency, percentage, and weighted mean determined the degree of relevance of blockchain as CA of Philippine HEIs. One-way ANOVA determined respondents' significant relationship (SR) with regard to blockchain awareness and identified SR of blockchain as CA over other colleges in terms of cost and differentiation. The results showed that students were most aware of the relevance of blockchain while professors were least aware. Both null hypotheses were accepted. There is no SR on the respondents' awareness on the use of blockchain. Respondents considered technology relevant and a foundational technology in recordkeeping. The research proposes EduChain Activity Flow Model to enhance recordkeeping in the academe. It will offer ample job opportunities to students in the field of blockchain. Also, the researcher suggests that administrators may incorporate blockchain training as part of faculty development. This research will pave the way for future researchers to study other aspects of blockchain in education.
\end{abstract}

Keywords: blockchain, blockchain technology, EduChain Activity Flow Model

\section{Introduction}

When Internet technology proliferated in the late 1980's, the world became a small place to keep everything virtually, and so is the rise of different technologies and software applications. Cryptographers' researches brought blockchain application to bitcoin when Nakamoto Satoshi introduced it in a white paper in 2009.

Through security, trust, consensus, and smart contracts, which are characteristics of blockchain, transactions become easier and distributable, securing both physical and digital assets (Sultan, Ruhi, \& Lakhani, 2018). Blockchain has undergone much transformation to the extent that it can be applied to the education industry, through record keeping. In addition, some institutions teach blockchain courses as electives. 
Blockchain is an electronic ledger, decentralized database which contains blocks of information encrypted by algorithms, where every transaction is unaltered and every block identifies secure decoded signature (Ray, 2018). Blockchain can be beneficial in the education industry because of having credentials in real time, adding trainings and learning to your portfolios, transferring knowledge, sharing credentials with potential employers, and facilitating job application process (Briggs, 2018). The joint technology of artificial intelligence and blockchain enables interactive learning that matches talents with the required skills in the industry (Mirzamany \& Hanif, 2018).

Since the outset of blockchain ten years ago, many researches have been directed to blockchain application in the field of education, although the technology is still nascent. Results showed that blockchain was a foundational technology that could be better than the Internet. The facets and advantages that blockchain can do to protect, share, and check the veracity of the credentials will revolutionize education globally. Blockchain capabilities, like verifiability, was explained in the presentation by Blockchain Research Group of the Knowledge Media Institute member (Riksen, 2017). This will affect record keeping of a person's credentials. Peer to peer system platform and disintermediation will help the macro-accreditation process (Mirzamany et al., 2018).

The study found a significant gap in knowledge within blockchain community regarding archival concepts, values, practices, and standards related to production, management, and preservation of authentic documents, creative and innovative as the many potential uses of blockchain for record keeping (Limeieux, 2018).

Smart contracts like Ethereum can be proven wherein learners receive a certificate from their institutions, accumulating proof for a full college degree. Records accumulated by students in the blockchain maybe accessed in real time since they are added automatically and can be shared with prospective employers (McArthur, 2018).

Viewing credentials securely in real time via smartphones or desktop computers and sharing it with potential employers and other educational institutions are beneficial. LinkedIn available jobs have tripled last year. Leading schools of business like New York University (NYU) Stern School of Business, Harvard Business Schools, and other educational institutions are offering Blockchain courses in their Master of Business Administration (MBA) programs (Ray, 2018).

As a forthcoming administrator of an academic institution, the researcher deemed it proper to investigate the topic precisely because of the need to update and upkeep the record keeping system of Philippine schools, so that students will understand their progress.

First, this will motivate them to be persistent and diligent in their studies. Second, they will see their long-term goals being achieved slowly but surely. Third, having credentials in real time, thinking that they have them at their own disposition is liberating and rewarding. Lastly, they will also know which subjects still need attention without bothering an administrative staff in the school. 
This is cost efficient and time saving on the part of school. The educational institution's image is upgraded and uplifted because the record keeping system is fully organized and that information is given in real time.

The confidence that blockchain brings to the institution is so vast that clients' trust is developed and enhanced. All stakeholders interested in a student's progress will refer to blockchain where everything is recorded. All data is transparent and immutable. Existing dilemma, concerns, and issues are resolved in real time, a great competitive advantage. Blockchain application in education covers many areas. One of them is digital school recording and credentialing, a blockchain framework based on Ethereum that can be developed and used by schools.

\subsection{Statement of Problems}

1. What is the perception of respondents with regard to their awareness of blockchain in terms of use of technology: features, cost, benefits, and safekeeping of records and school records? 2. Is there a significant relationship between the respondents' perception and their awareness of the use of blockchain technology in higher education institutions? 3. What is the competitive advantage of blockchain technology over other colleges and universities as perceived by respondents in terms of cost and differentiation? 4. How will the blockchain framework enhance record keeping techniques in terms of awareness and relevance?

\subsection{Theoretical and Conceptual Framework}

The theoretical framework of this study is based on two dimensions. The first is the technology behind blockchain and the second is the competitive advantage concept as applied to school setting. The concept of blockchain is composed of knowledge procurement cycle and distributed learning ledger. This is where the idea of blockchain technology for record keeping as applied to education industry will be anchored. Smart contracts, built on Ethereum platform as applied to education industry, belonged to the second generation of blockchain. The proponent used convergent parallel design in the conceptual framework.

\subsection{Hypotheses of the Study}

The following null hypotheses were tested.

$\mathrm{H}_{1}$ : There is no significant relationship between the respondents' perception and their awareness of the use of blockchain technology in higher education institutions.

$\mathrm{HO}_{2}$ : There is no significant relationship between blockchain technology as a competitive advantage over other colleges and universities in terms of cost and differentiation.

\section{Methods and Materials}

Exploratory design, and convergent parallel design (mixed method) were utilized in this study. Both qualitative and quantitative data were gathered simultaneously. Gathered data were collated, merged, combined, related and compared, then interpretation was formulated with the aid of statistical tools. 


\subsection{Description of Respondents}

The participants were industry practitioners like smart contracts software developers, professors who attended the seminars, and students from Cavite State University and other colleges where blockchain is taught as an elective subject. 20 out of 193 or $10.36 \%$ of the respondents came from Google online survey, including industry practitioners, professors, and students. The rest of the survey was administered face to face. Ten (10) people answered the structured questionnaire.

\subsection{Sampling Technique}

Purposive, quota, random and convenience sampling techniques were utilized in this study. First, the researcher employed purposive sampling because only professors have been trained on blockchain technology and students are currently enrolled in blockchain. In addition, industry practitioners were chosen to answer the survey questionnaire.

Second, the proponent used quota sampling. Only $10 \%$ among the students who were taking up blockchain as an elective subject were randomly asked to answer the survey questionnaire. Third, once the number of participants for the survey was identified, the proponent just picked randomly respondents who were available during that time to answer the survey questionnaire.

\subsection{Research Instruments}

Self-made survey and structured questionnaire were the instruments used and administered separately. The researcher also placed the survey online using Google documents. The self-made survey questionnaire composed of three (3) parts: The first part was the demographic profile of respondents. The second part had six (6) multiple choice questions. Participants had to answer a 5-point Likert scale about blockchain awareness. The third part had 2 multiple choice questions. Participants had to fill a 5-point Likert scale about relevance of blockchain as a competitive advantage for HEI's.

The questionnaire supported the survey in which participants came from a dynamic background. The information gathered from the structured questionnaire was incorporated in this study to add value, validate, and to strengthen the findings of this research.

\subsection{Statistical Treatment of Data}

The research instruments were retrieved, collected, collated, tallied, tabulated, cross tabulated, and computed. Data were subjected to data analysis and treatment, using the following statistical tools:

Likert scale determined the respondents' awareness of blockchain and relevance of blockchain technology as a competitive advantage over other colleges and universities in terms of cost and differentiation. Frequency and percentage of distribution revealed which among the respondents have placed the greatest emphasis on competitive advantage if used in relation to blockchain technology (SOP \#3).

Weighted mean, employed for SOP \#1, determined which among the awareness factors has the highest level of occurrence. SOP \#3 revealed which among the respondents consider cost 
and differentiation as having the highest competitive advantage when applied to blockchain technology.

SOP \#2, utilized for one-way ANOVA, found out that there is a significant relationship in the respondents' perception with regard to their awareness of the use of blockchain technology in higher education institutions. SOP \#4 determined the significant relationship between blockchain technology and competitive advantage over other colleges and universities in terms of cost and differentiation. Both statements of problems made use of Microsoft Excel in treating One-Way ANOVA. EduChain Activity Model Flow answered SOP \#5 on how blockchain framework will enhance record keeping techniques in terms of awareness and relevance.

\section{Discussion}

The presentation and analysis of data are organized according to the specific questions under the statement of the problem. In this chapter, results are discussed in detail. Data are analyzed and presented in tabular form; explanations included to emphasize clarity.

A total of 193 respondents answered the survey questionnaire. 18 or $9.33 \%$ were industry practitioners, 18 or $9.33 \%$ were professors, and 157 or $81.34 \%$ were students. The three groups were given the same set of survey questionnaire.

Another structured written questionnaire was floated to get the qualitative data from other respondents. There were ten (10) respondents. The results were used to support the quantitative data elicited from the survey questionnaire. Some of the answers were included in the discussion of results which validated some of the responses of the respondents in the survey questions.

\subsection{SOP 1}

SOP\#1 discusses the question: What is the respondents' perception with regard to their awareness of blockchain?

Table 1

Mean of Respondents on the Perception on Awareness of Blockchain Technology

\begin{tabular}{|c|c|c|c|c|c|}
\hline Indicators & $\begin{array}{c}\text { Industry } \\
\text { Practitioners } \\
\text { WM }\end{array}$ & $\begin{array}{c}\text { Professors } \\
\text { WM }\end{array}$ & $\begin{array}{c}\text { Students } \\
\text { WM }\end{array}$ & $\begin{array}{c}\text { Overall } \\
\text { Weighted } \\
\text { Mean }\end{array}$ & DR \\
\hline
\end{tabular}

Perception of respondents with regards to their awareness on blockchain in terms of :

\begin{tabular}{lllllc} 
1. Extent on use of technology & 3.78 & 3.15 & 3.79 & 3.57 & A \\
2. Features & 3.59 & 3.46 & 3.74 & 3.60 & A \\
3. Cost & 3.17 & 3.24 & 3.73 & 3.38 & MA \\
4. Benefits & 3.80 & 3.56 & 3.73 & 3.70 & $\mathbf{A}$ \\
5. Safekeeping of Records & 3.57 & 3.33 & 3.74 & 3.55 & $\mathbf{A}$ \\
6. School Records & 3.65 & 3.57 & 3.73 & 3.65 & $\mathbf{A}$ \\
\multicolumn{1}{r}{ Grand Mean } & $\mathbf{3 . 5 9}$ & $\mathbf{3 . 3 9}$ & $\mathbf{3 . 7 4}$ & $\mathbf{3 . 5 7}$ & $\mathbf{A}$ \\
\hline
\end{tabular}

Legend : 4.50-5.00 Extremely Aware, 3.50-4.49 Aware,

2.50-3.49 Moderately Aware, 1.50-2.49 Moderately Not Aware, 1.00-1.49 Not Aware

Table 1 presents the mean on the perception of respondents' awareness of blockchain technology. With regard to the first indicator, which is "extent on use of technology," for industry 
practitioners, it appears that they are "aware (A)" with a weighted mean of 3.78. Similarly, students revealed that they are "aware (A)" with a weighted mean of 3.79, while professors showed that they are "moderately aware (MA)" with a weighted mean of 3.15. Moreover, taking the overall impression "on the extent on the use of technology" in terms of ease of use, incorruptible and efficient, the result reveals that the respondents are "aware (A)" of blockchain technology with an overall weighted mean of 3.57 .

Moreover, concerning the second indicator "features," table 1 reveals that industry practitioners have a weighted mean of 3.59 which means that this group of participants are "aware(A)" of blockchain technology with a weighted mean of 3.59. Likewise, students reveal that they are "aware(A)" of blockchain technology with a weighted mean of 3.74. However, professors appear to have a "moderately aware (MA)" response regarding blockchain technology with a weighted mean of 3.46. Furthermore, with regard to the overall impression in terms of features, the information reveals that the participants have a grand mean of 3.60 meaning "aware (A)" of blockchain technology in terms of security, trust, and being permissionless.

In relation to the third indicator "cost," table 1 further illustrates that the industry practitioners revealed that they are "moderately aware (MA)" of this nascent technology with a weighted mean of 3.17, while professors responded "moderately aware (MA)" with a weighted mean of 3.24. Lastly, student participants are "aware (A)" with a weighted mean of 3.73. Among the three groups, Students revealed the highest weighted mean which can be attributed to class lessons which conveyed a lot of knowledge about blockchain as being economical, sustainable, and direct without a middleman.

Overall, these respondents have a weighted mean of 3.38 which means that in terms of cost, they are "moderately aware (MA)" of the cost of blockchain technology. This is due to the fact that it is a very infant technology and its application is only limited to an introductory course as an elective subject in the education industry. However, this technology is used in other fields such as banking. For example, Union Bank of Philippines has been using this technology in rural areas where there are no banks.

Based on the fourth indicator "benefits," table 1 states that industry practitioners are "aware (A)" of blockchain with the highest weighted mean of 3.80, followed by students with a weighted mean of 3.73 and professors with a weighted mean of 3.56. Although they have different level of awareness in terms of benefits, with the professors being the least in terms of numerical output, overall, all the three groups of respondents are still aware of the benefits of blockchain as being decentralized, verifiable, and reliable with an overall weighted mean of 3.70 meaning "aware (A)." Overall, all respondents are "aware (A)" of the characteristics of blockchain in relation to school records.

Table 1 presented the fifth indicator which further illustrates that in terms of safekeeping of records, industry practitioners are "aware (A)" with a weighted mean of 3.57, followed by students who are similarly "aware (A)" with a weighted mean of 3.74. However, professors are "moderately aware (MA)" with a weighted mean of 3.33, which means that they have little information about blockchain. The overall weighted mean of the respondents is 3.55 which means "aware (A)." This only shows that in terms of safekeeping of records, the respondents have 
knowledge in terms of being searchable, transparent and has the characteristic of being anonymous, especially when doing the transaction.

Lastly in table 1, the sixth indicator shows that in terms of school records, industry practitioners, professors, and students are "aware (A)" with a weighted mean of 3.65, 3.57 and 3.73 respectively. Overall, the respondents are "aware (A)" with a weighted mean of 3.65. This only shows that respondents are very open-minded with blockchain having automatic transfer of credits, accessible, and paperless. The overall impression on the awareness of respondents in terms of the six variables, as seen in table 4, shows that the three groups of respondents namely, the industry practitioners, professors, and students are "aware," with a grand mean of 3.57. This only shows that blockchain technology is gaining importance in the field of education as evident by the result of the survey in this study.

Table 1 shows that as for the overall impression on the awareness of blockchain technology, the grand mean is pegged at 3.57 which means "Aware." This denotes that all respondents, industry practitioners, professors and, students, have knowledge of blockchain technology in general.

The following literature supports the "awareness" of indicators stated in this study. Higher education institutions have tried blockchain as a means of streamlining the distribution of grades and other school documents with probable employers and as a substitute for recordkeeping programs. Aside from the ease of access, this innovation has been quoted as a possible cost-saver for both the student and the employer, with the employer reducing cost by eliminating the use of middlemen (Riddell, 2017).

"Bitcoin" has set the forefront in the development of blockchain technology which provides advantages in the field of education. The probable involvement of this technology was inspected by a research done by the Joint Research Center (JRC). It took into consideration the "incorruptible" feature of this technology in the field of training, virtual certificate, utilizing institutional appointments, and the safety of intellectual property (Raval, 2018).

Blockchain is defined as "an incorruptible digital ledger of economic transactions that can be used to record not just financial transactions but everything of value" (Tapscott, D. \& Tapscott, A. 2017). Student transcripts, transferred credentials, school lunch, attendance, standardized testing grades, and possibly more could be placed on a distributed ledger to reduce paperwork and provide an efficient school system process (Impact Chain Lab, 2017).

This technology provides a high level of security because a decentralized ledger is difficult to hack. Some schools and colleges implemented blockchain and few others are testing it. Aside from cost cutting and security, schools need not act as document keepers (Matthews, 2017). Although this innovation is in its early stages, its power, relative security especially from hacking, and resilience make it a good choice to several schools and colleges such as Massachusetts Institute of Technology (MIT) and Open University (Jirgensons \& Kapenieks, 2018).

Blockchain forms trust through encryption, by permitting members to securely transact business without the use of an intermediary (Sultan, Ruhi, \& Lakhani, 2018). Trust comes with 
using blockchain. Only trusted individuals can be part of the chain and only trusted members can have access. Trust matters when transacting with numerous authorities from several areas. Schools can create trustworthy systems and procedures. Tokens are transferred to trusted parties. These tokens rest on the accomplished credits taken in students' records. So, it creates globally, trusted and united platform for higher education. (Alammary et al., 2019).

Fairness means having the same privileges that everybody has on a blockchain. The sincerity, borderless, and permissionless qualities of this technology and the infrastructure can give everyone the same access to blockchain. Anybody can have a virtual wallet on the blockchain network. All educational institutions, professors, and learners can access it every day, thereby, circumventing prejudice (Chen et al., 2018). Blockchain in its entirety is permissionless. After the whole transactions and messages have been proven authentic, they become noticeable to all members in the chain. This guarantees that there is transparency since all documents can be traced back to its source (Azogu et al., 2019).

Decentralized ledger technology (DLT) is removing the middleman, known as disintermediation (Ark, 2018). DLT also has similar advantages. It promises certainty and enables trust between the two parties. By eliminating intermediaries, it permits more people to have an interaction. The exclusion of intermediary allows faster speed and lesser costs (Fyrigou-Koulouri, 2018).

It provides numerous learning marketplaces from all fields. TeachMePlease is a Russian pilot on the Disciplina system where teachers and learners encounter. It helps learners to scout and pay for programs, documented by educational organizations (Ark, 2018). An independent learning platform could be established between a trainer and a trainee and the terms and conditions for training like projects, tasks, fee, and training duration could be agreed upon between both parties. This agreement could be stored as smart contracts for transparent and secure execution, thereby eliminating the concept of middleman who can increase the cost in this way (Mittal, 2018). This nascent technology allows entries that are permanent, transparent, and searchable, which permits peers to see previous transactions and histories.

Every transaction is updated and forms a new block and added to the end of a "chain" after an agreement has been reached that the information is authentic and genuine. The system checks new entries, started, authenticated, recorded and decentralized. With blockchain, encryption replaces middlemen as the guardian of trust, with all members processing to validate the truthfulness of the entire transaction (Ark, 2018). Blockchain has plenty of advantages like anonymity. Peers can transact in blockchain in trusted transactions without exposing their real personalities, which reduces the amount of time spent doing the business.

This innovative technology carries an important role in education which includes ample amount of security, low cost, improving learners' assessments, improved control of getting information, transparency and greater liability, validation of identity, improved trust, better efficiency of students' credentials management, improved career paths of students, and interactivity of students.

Moreover, the education industry will significantly derive benefits from lower costs offered by blockchain technology, with storage, associated transaction, and the cost of 
maintaining credentials. Using permissioned or permissionless decentralized network, which can be accessed from anywhere, will reduce the cost of old way of storing data in the cloud. Schools, colleges, and universities can provide a trusted network by devising secure and reliable blockchain platforms (Alammary et al., 2019).

This infant technology, when applied to education, has developed an assessment and management tools for students' documents that are permanent, transparent, and sustainable while giving users unwavering access to information. The software has a system to record, store, and keep documents. It also provides educational institutions with lower administrative costs. Bureaucracy is limited because interaction is straight forward (Jirgensons \& Kapenieks, 2018).

University of Nicosia located in Cyprus was the first school to utilize blockchain-based certificates in which the identity can be verified if it is authentic through blockchain technology. Sony also recognized the budding technology for verifying scholastic accomplishments. The Open University, an adult education institution, is attracted to this technology because of the diverse background of its students (Riksen, 2017).

A students' credentialing system based on blockchain was created by Sony Corporation and Sony Global Education (SGE). Academic managers utilize this innovation to combine and control learners' information from different educational institutions, and devise a system founded on students' experiences and grades. Moreover, as a proof of their formal and non-formal trainings, learners can share their credentials with potential employers and other interested stakeholders and can guarantee verification if requested. The distributed ledger also assists users to transfer credentials and credits from one school to another, authenticate documents across different educational institutional systems, and combine with several learners' facilities in a single repository of data (Shilov, 2018).

The majority of paper-based college and graduate studies diplomas, training certificates, and many other important credentials tarnish and some are misplaced and lost when kept for more than a decade or so. Once stored in blockchain, the data about students will be stored permanently, no one can fake it. With the owner's permission, one can easily access the data. Instead of collecting traditional certificates, students can take advantage of paperless recording of information stored in blockchain, which will be accessible to potential employers globally. Blockchain, as an innovative and nascent technology can support the universal educational model, making it more enjoyable, relevant, cheaper and accessible (Mirzamany \& Hanif, 2018).

\subsection{SOP 2}

SOP \#2 tackles the question: Is there a relationship in the respondents' perception with regard to their awareness of the use of blockchain technology in higher education institutions? To address this question, One-way analysis of variance (ANOVA) was used and computed using Microsoft Excel. 
Table 2

ANOVA - Perception of Respondents on Awareness of Blockchain

\begin{tabular}{lcccccr}
\hline \multicolumn{1}{c}{ Source of Variation } & SS & \multicolumn{1}{c}{ df } & MS & $F$ & P-value & Fcrit \\
\hline Between Groups & 0.18 & 5.00 & 0.04 & 0.70 & 0.63 & 3.11 \\
Within Groups & 0.62 & 12.00 & 0.05 & & & \\
& & & & & & \\
Total & 0.80 & 17.00 & & & & \\
\hline
\end{tabular}

Table 2 shows that the F statistic of 0.70 is lower than the F critical value of 3.11 . So, there is no reason to reject the null hypothesis. The finding is not significant; therefore, the null hypothesis is accepted, which means that there is no significant relationship in the perception of respondents with regard to their awareness of the use of blockchain technology in higher education institutions.

Indeed, blockchain is gaining momentum in the education industry as evident by the articles, blogs, studies, and researches done on this innovative platform. Many countries like Malta had a contract with Learning Machine so that all educational documents in the country are stored in blockchain (Jenkinson, 2019).

Massachusetts Institute of Technology in the US had been a long-time advocate of blockchain technology for education, and this has been evident by Blockcerts, diploma issued to their graduates. It was part of their pilot program of issuing the digital certificates to 111 graduates who became the initial recipients of diplomas on their mobile phones via an app. Later, Learning Machine and MIT Registrar's office had a tie-up. The platform is called Blockcerts Wallet, which authorizes students to share certificates with prospective employers, which can be easily authenticated, validated, and hacker proof, in addition to the paper format issued before. This can also be easily shared with peers, friends, relatives, and acquaintances. This breakthrough in technology is the first globally, because this will result in the students' autonomy over his own credentials (Durant \& Trachy, 2017).

Other countries are implementing blockchain in records management like Britain and Canada. The United Arab Emirates through The British University in Dubai (In association with University of Nicosia) is into blockchain already (El Nokiti \&Yusof, 2019).

\subsection{SOP 3}

SOP \#3 tackles the question: What is the competitive advantage of blockchain technology over other colleges and universities as perceived by respondents in terms of cost and differentiation? 


\section{Table 3}

\section{Mean of Respondents' Perception on the Relevance of Blockchain Technology as a Competitive Advantage in Terms of Cost and Differentiation}

\begin{tabular}{lccccl}
\hline \multicolumn{1}{c}{ Indicators } & $\begin{array}{c}\text { Industry } \\
\text { Practitioners } \\
\text { WM }\end{array}$ & $\begin{array}{c}\text { Professors } \\
\text { WM }\end{array}$ & $\begin{array}{c}\text { Students } \\
\text { WM }\end{array}$ & $\begin{array}{c}\text { Overall } \\
\text { Weighted } \\
\text { Mean }\end{array}$ \\
\hline $\begin{array}{l}\text { Relevance of blockchain as a competitive advantage in terms of : } \\
\text { 1. Cost }\end{array}$ & & & & & \\
1. 1. Worth the value of your money & 3.33 & 3.61 & 3.64 & 3.53 & MR \\
1. 2. Quality of service & 3.22 & 3.67 & 3.49 & 3.46 & MR \\
1. 3. Cheapest price & 3.11 & 3.28 & 3.64 & 3.34 & MR \\
2. Differentiation & & & & $\mathbf{3 . 5 4}$ & $\mathbf{R}$ \\
2. 1. Focus & 3.33 & 3.33 & 3.64 & 3.43 & MR \\
2. 2. Unique Selling Proposition & 3.44 & 3.67 & 3.57 & 3.56 & $\mathbf{R}$ \\
2. 3. Partnership with other businesses & 3.56 & 3.67 & 3.69 & 3.64 & $\mathbf{R}$ \\
\hline
\end{tabular}

Statistic al Limit : 4.50-5.00 Extre mely Relevant, 3.50-4.49 Relevant,

2.50-3.49 Moderately Relevant , 1.50-2.49 Moderately Not Relevant, 1.00-1.49 Not Relevant

Table 3 presents the mean on the respondents' perception of relevance of blockchain as a competitive advantage in terms of cost. For the first indicator, which is "worth the value of your money," students revealed that blockchain technology is "relevant (R)" with a weighted mean of 3.64; while professors showed that this technology is "relevant (R)" with a weighted mean of 3.61. Lastly, for industry practitioners, it appears that they are "moderately relevant (MR)" with a weighted mean of 3.33. Taking the overall impression on the relevance of blockchain technology, as a competitive advantage in terms of cost and under the indicator "worth the value of your money," the result shows that among the respondents' perception of the technology is "moderately relevant (MR)" with an overall weighted mean of 3.53.

Furthermore, table 3 presents the mean on respondents' perception of relevance of blockchain as a competitive advantage in terms of cost. For the second indicator, which is quality of service, professors revealed that blockchain technology is "relevant (R)" with a weighted mean of 3.67; while students showed that this technology is "moderately relevant (MR)" with a weighted mean of 3.49. For industry practitioners, it appears that industry practitioners are "moderately relevant (MR)" with a weighted mean of 3.22. Taking the overall impression on the relevance of blockchain technology as a competitive advantage in terms of cost under the indicator "quality of service," the result shows that among the respondents' perception, the technology is "moderately relevant (MR)" with an overall weighted mean of 3.46.

In addition, table 3 presents the mean on the respondents' perception on the relevance of blockchain as a competitive advantage. For the third indicator, which is "cheapest price," students showed that blockchain technology is "relevant (R)" with a weighted mean of 3.64, while professors showed that this technology is "moderately relevant (MR)" with a weighted mean of 3.28. Industry practitioners revealed that it is "moderately relevant (MR)" with a weighted mean of 3.11. Taking the overall impression on the relevance of blockchain technology in terms of cost, under the indicator cheapest price, the result shows that the technology is "moderately relevant 
(MR)" with an overall weighted mean of 3.34. Furthermore, for the overall impression on the relevance of blockchain technology as a competitive advantage in terms of cost, it is moderately relevant with a grand mean of 3.44 .

The education industry will be shaped and changed by blockchain technology, which is more enjoyable, cost efficient, and available in real time. In recent years, several studies have focused on how blockchain can be utilized in the field of education. Record keeping of training courses, learning, and studies can be written in the chain. This can change the way credentials are stored from the physical to virtual storage, which is authenticated, verified, and available in real time. This new way of doing things coupled with artificial intelligence (AI) can make a difference in one's life by acquiring new skillset needed by the market. The business and technical industry can effectively match the right skills with required skills by the labor market (Mirzamarsky \& Hanif, 2018).

Moreover, table 3 illustrates the mean on the respondents' perception on the relevance of blockchain, as a competitive advantage in terms of differentiation. For the first indicator, which is "focus," students revealed that blockchain technology is "relevant (R)" with a weighted mean of 3.64, while professors showed that this technology is "moderately relevant (MR)" with a weighted mean of 3.33. Lastly, for industry practitioners, it appears that they are "moderately relevant (MR)" with a weighted mean of 3.33. Taking the overall impression on the relevance of blockchain technology, as a competitive advantage in terms of differentiation under the indicator focus, the results show that for the respondents' perception, the technology is "moderately relevant (MR)" with an overall weighted mean of 3.43 .

Table 3 presents the mean on the respondents' perception on relevance of blockchain as a competitive advantage in terms of differentiation. For the second indicator which is "unique selling proposition" (USP), professors showed that blockchain technology is "relevant (R)" with a weighted mean of 3.67, while students showed that this technology is "relevant (R)" with a weighted mean of 3.57. For industry practitioners, it appears that industry practitioners are "relevant (R)" with a weighted mean of 3.44. Taking the overall impression on the relevance of blockchain technology in terms of differentiation under the indicator USP, the result shows that the technology is "relevant (R)" with an overall weighted mean of 3.56.

Moreover, for the third indicator which is "partnership with other businesses," students revealed that blockchain technology is "relevant (R)" with a weighted mean of 3.69, while professors showed that this technology is "relevant (R)" with a weighted mean of 3.67. Lastly, for industry practitioners, it appears that it is "relevant (R)" with a weighted mean of 3.56. Taking the overall impression on the relevance of blockchain technology in terms of differentiation, under the indicator "partnership with other businesses," the result shows that the technology is "relevant (R)" with an overall weighted mean of 3.64.

Furthermore, for the overall impression on the relevance of blockchain technology as a competitive advantage in terms of differentiation, it is relevant with a weighted mean of 3.54. Concerning the idea that blockchain offers the less cost, eliminating the middlemen makes blockchain technology efficient and cost effective. What is saved are fees designed to be paid to professionals who will authenticate the validity of the information. In addition, blockchain is 
preferred due to its competitive advantage. Law firms and stock photo agencies may use blockchain to provide new services advantageous to both buyers and content creators.

\subsection{SOP 4}

SOP \#4 analyzes the question: Is there a significant indicator on blockchain technology as to its competitive advantage over other colleges and universities in terms of cost and differentiation? One-way analysis of variance (ANOVA) was used to determine this hypothesis. One-way ANOVA was computed using Microsoft Excel.

The following are the results of the study:

Table 4

ANOVA - Perception of Respondents on Relevance of Blockchain

\begin{tabular}{lllllll}
\hline \multicolumn{1}{c}{ Source of Variation } & SS & df & MS & $F$ & P-value & F crit \\
\hline Between Groups & 0.16 & 8.00 & 0.02 & 0.45 & 0.86 & 3.23 \\
Within Groups & 0.41 & 9.00 & 0.05 & & & \\
Total & 0.57 & 17.00 & & & & \\
\hline
\end{tabular}

Table 4 illustrates that the F statistic of 1.19 is lower than the F critical value of 2.22. So, there is no reason to reject the null hypothesis. The finding is not significant; therefore, the null hypothesis is accepted, which means that there is no significant relationship between blockchain technology as a competitive advantage over other colleges and universities in terms of cost and differentiation.

For marketplaces to flourish, shoppers and vendors require to trust the data they utilize to resolve with whom to do business. When there is a disproportionate amount of information between the two, valuable trades do not happen.

Blockchain technology, with the reduced costs of authentication, makes market secure and efficient, thereby increasing different types of transactions (Catalini, 2017). The utilization of blockchain technology for the development of trustworthy and transparent records is seen as a unique feature and selling point in many existing and future platforms of blockchain technology (Limieux, 2016).

Programming tasks, like automation, makes blockchain more attractive. It reduces costs and improves productivity. These alone are the core characteristics of competitive advantage. The removal of disintermediation means lower fees included in the transaction. Smart contracts provide a solution to formation and implementation of the legal contracts without human intervention. In short, it is automated. Business transactions executed in blockchain is faster than the traditional way of doing business. Security and decentralization make this technology unique. 
Blockchain is differentiated with these features. This infant technology has plenty of advantages to offer anyone who is willing to harness the benefits it has to offer. Many firms have confidence that blockchain will certainly assist them to gain a competitive advantage (Silva, 2019).

\subsection{SOP 5}

SOP \#5 deals with the question of how will the blockchain framework enhance record keeping techniques in terms of awareness and relevance? The proponent came up with the blockchain framework named EduChain Activity Model Flow. It is based on Blockchain 2.0 generation, which will run on Ethereum platform with Ether as its currency. The model will run smart contracts. There are three diagrams: physical flow, logical flow, and EduChain Activity Model Flow.

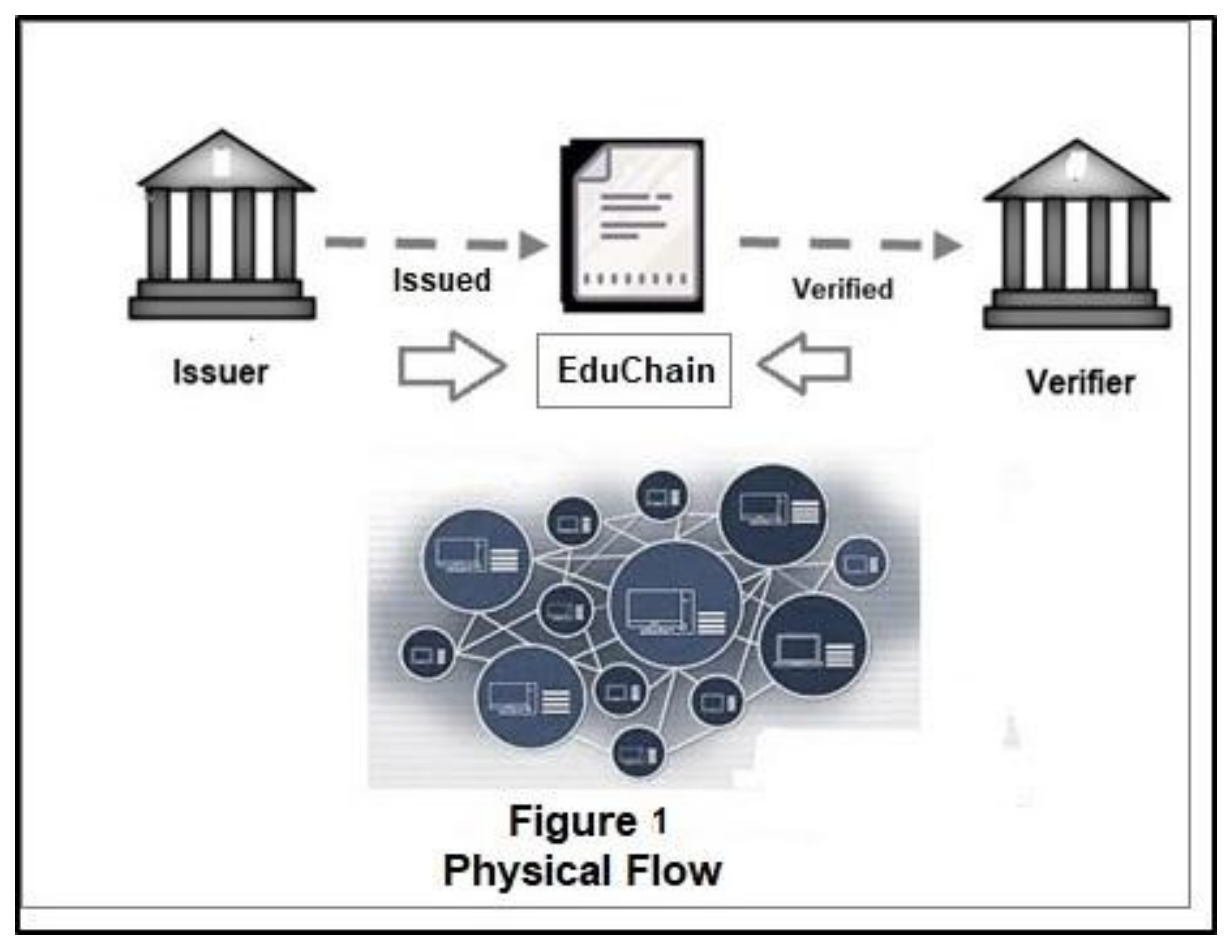

Figure 1 presents the physical flow of documents from the issuer, which is the educational academic institution. Once issued and deployed in the EduChain decentralized network, it will be authenticated. External stakeholders like potential employers can verify and validate a student's digital certificate by accessing the Educhain. 


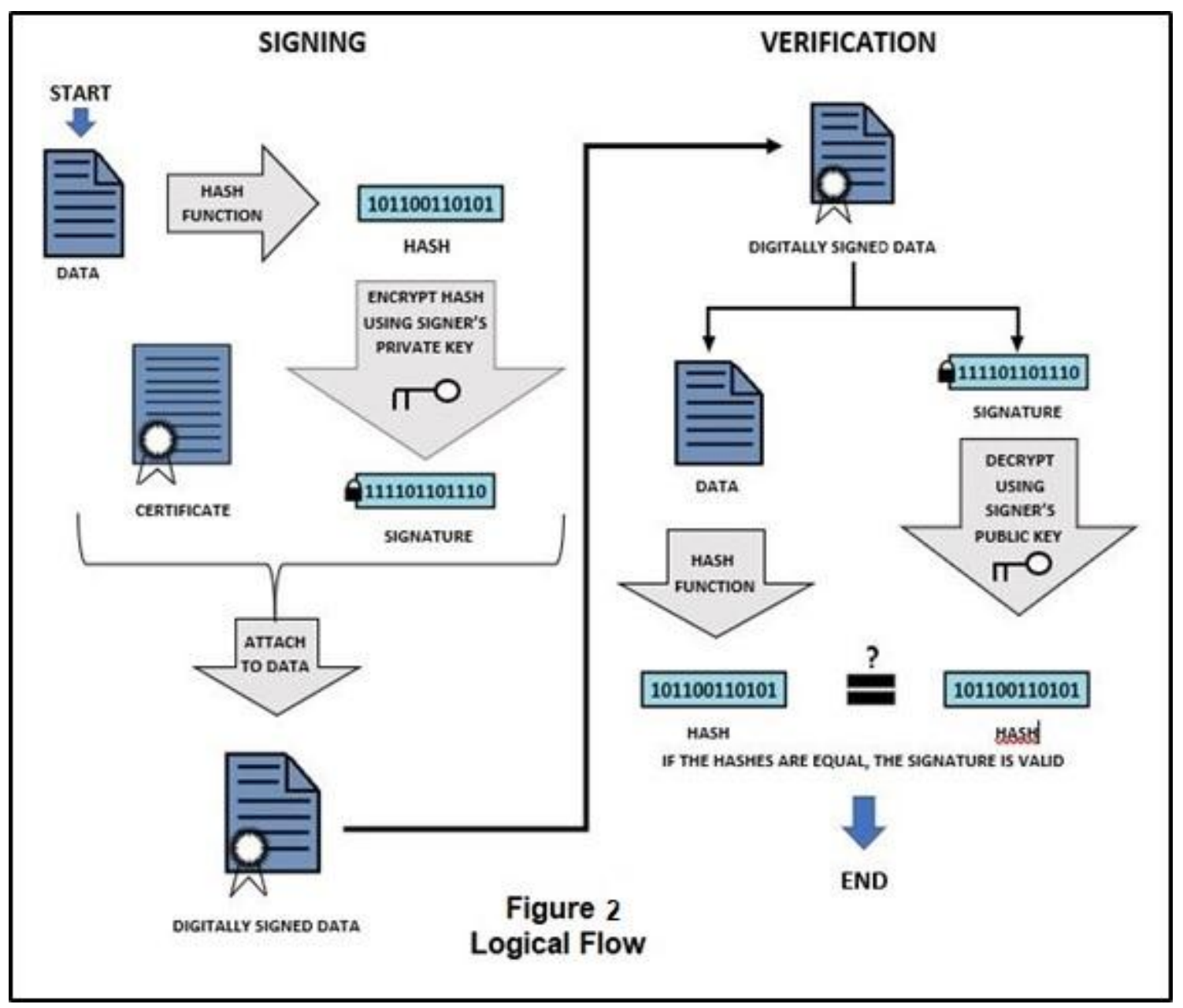

Figure 2 presents the logical flow of blockchain which has two parts, the signing and the verification of digital signatures. The back-end logical flow explains the digital signing and verification of digital signature or hash. Initial process will start with the signing of the document.

Data are converted to the hash number that contains series of 1's and 0's. The hash will be scrambled and encoded in the EduChain. After the hash has been coded, it will be locked using the owner's private key, then attached to the document itself (soft copy). The digital signature will originate from the school registrar, who is the issuer. Now, if a student wants to get a credential digital signature from the institution, he or she will have to pay the school a certain fee using Ether. Then a digital cert hash (digitally signed data) will be sent to the requesting party, which is the student.

The next part discusses the way documents are verified as the left side of the diagram reveals. Once the student shares the (digitally signed data), a digital cert hash, which is composed of alphanumeric characters, will pass again into the hash function and the hash (which contains the private key), will appear. On the right side of the diagram, the digitally signed document is still locked. In order to view the document in blockchain, the potential employer, where the student shares the data, will decode the private key by entering the signer's public key. Now, after using the signer's public key, the two hashes will be compared by the EduChain. If both hashes are equal, then the certificate is valid. 


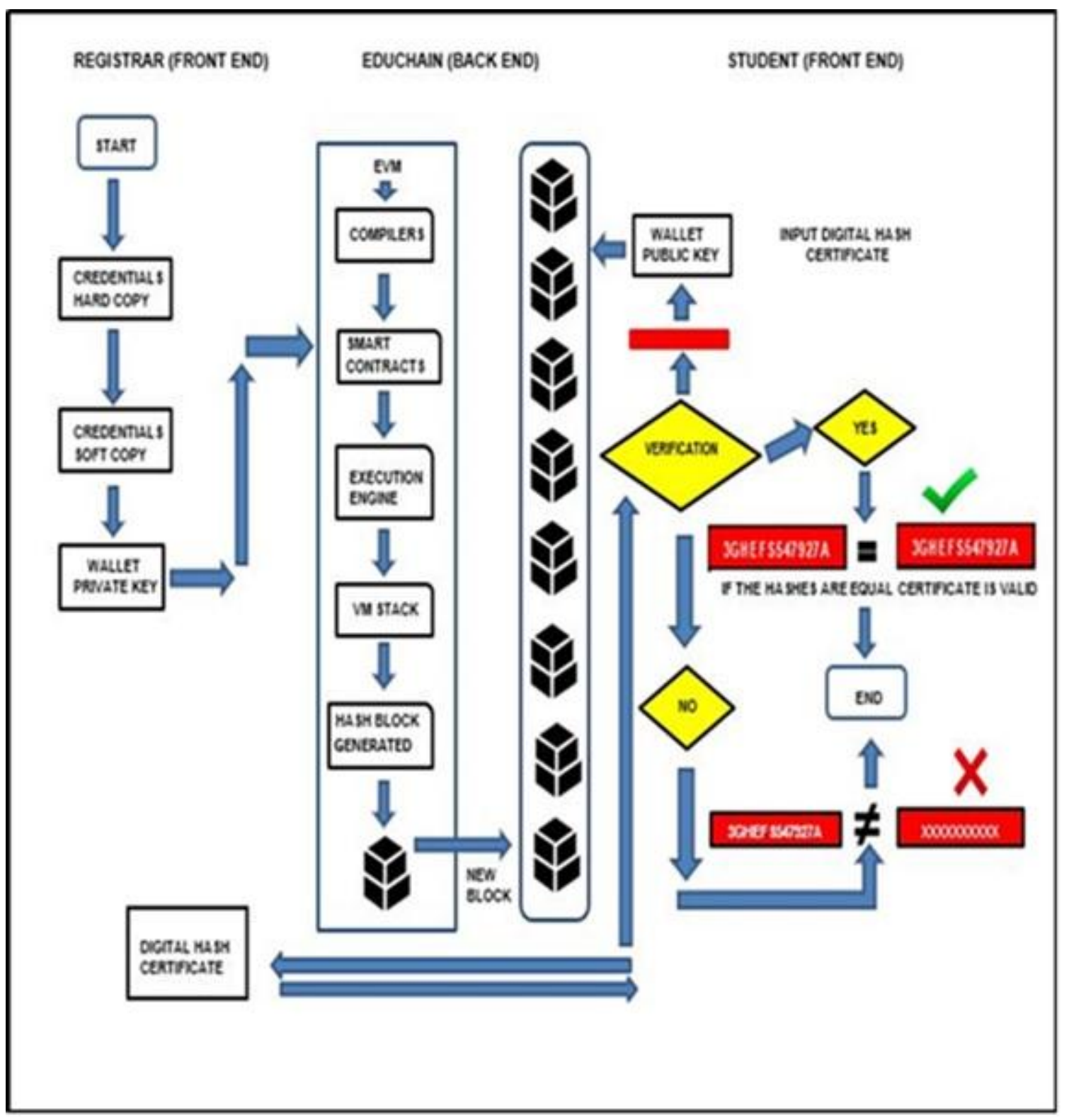

Figure 3

EduChain Activity Model Flow

Figure 3 presents EduChain Activity Model Flow, which starts the flow from the registrar. The input of the registrar, hard copy of diplomas, certificates, grades, training, and other credentials, is scanned and converted into soft copy. However, before the registrar can initiate transaction, a virtual wallet for the registrar must be created so that all credentials of students will be placed here. The registrar's wallet contains the private key of the user. After creating the registrar's virtual wallet, the registrar should have Ether, the currency used in the Ethereum platform. Now, the registrar can commence the transaction having a registrar's virtual wallet and Ether. This is the first part of the diagram, the front end.

The Ethereum Virtual Machine (EVM) uses the Turing language which is based on C++ programming language. The EVM initiates its operation by using compilers. These compilers process smart contracts in which private key from the registrar's virtual wallet is attached. After smart contracts are processed by the compiler, it goes directly to the execution engine. When the 
execution engine is done with the logical operation from the contracts, it passes through the virtual machine (VM) stack. Finally, in the backend, a block will be created with a unique hash which will be compiled and published into the blockchain as a new block. Every block represents a unique academic credential. The student will be given the digital certificate containing the hash. A hash is a series of alphanumeric characters, composed of numbers and letters scrambled. Students may opt to share these digital credentials to potential employers. Nevertheless, before the students can share it with prospective employers, the student will request access to the blockchain network of the school. The student must pay Ether to the school, to be able to get the verified digital certificate.

The student may share the EduChain public key with the employer. Then, the potential employer will take the student's private key access in EduChain activity flow model and verify the document. If the hashes are equal, the certificate is valid. On the other hand, if the hashes do not match, which means not equal, the certificate is not valid. Thus, the verification process ends there. The output used is mobile devices, laptops, or desktop computer, etc. This is the last part of the diagram, the front end for students.

Furthermore, for a start, the proponent just thought of the traditional procedure of how request of documents from the school flows. The same system will be applied in the EduChain, only with a twist. In blockchain, a currency in the form of Ether will be used. Moreover, the credentials and other documents will have several copies of the file as the smart contracts are executed, whereas in traditional process, there is only one copy. Documents, in the form of smart contracts, will be there permanently. All the advantages of blockchain will be experienced by students.

In terms of awareness, although all respondents are aware of blockchain technology, there is a certain degree of awareness of every respondent. For instance, the least aware of the respondents are the professors because, first, the education industry is still untapped, not in the record keeping part. Few white papers, articles, blogs are written about this. Though in the US Blockcerts are already issued, in terms of written documents about recordkeeping, there are really few. In fact, when the proponent was still reading literature about recordkeeping in blockchain, many challenges have been encountered due to lack of resources.

The first step done about awareness of blockchain was when NEM Philippines conducted their seminar. Another partner company of NEM is in Cavite which trained professors from Cavite State University and its eleven (11) satellite campuses. However, despite all the hindrances, it is still worth doing.

In terms of relevance, the Educhain model will change the way documents are stored. First, it is already stored in students' mobile devices, as well as in the cloud, so it is easy to use, accessible, permanent and permissionless. Second, it is safe, trusted and secure, no one can fake it, and it is immutable and incorruptible. Third, it is efficient because you can access the files in real time.

Fourth, no intermediary is needed to access the file. The digital hash serves as a password to the student and marks the end of the transaction. It is cost effective and economical because you will only request the information once, and it is owned by the student permanently. In case 
there is war, or any fortuitous event or calamities, it will not get lost nor stolen; therefore, it is sustainable. It is stored in a shared ledger, so it is decentralized. Anyone in the blockchain can verify the authenticity of the document, so it is reliable and transparent. If someone wants to search for the document, they can do so because anything on the blockchain is searchable. Since data are encrypted, what you see only are digital hashes composed of 1's, 0's and so, your data is anonymous.

Lastly, before a chain of block is validated, everyone in the chain should agree that the entry made is valid, so consensus among the group are made. In Ethereum platform, smart contracts are automatically executed once certain conditions are met.

Finally, EduChain Activity Model Flow is a new storage paradigm that will change the way recordkeeping and storage of documents as well as credentials will be done in the education industry. This paradigm shift of recordkeeping in the education industry will improve and enhance recordkeeping techniques and eliminate intermediary. It is also decentralized, permanent, secure, transparent, and permissionless. In addition, it is paperless because it is cloud-based, done in real time. Most significantly, the students' own their credentials as they will be available on their mobile devices, laptops, and computers.

\section{Conclusion}

To conclude, the study reveals that students are the most aware of the advantages of blockchain technology because they are taking up blockchain as an elective and because they are tech-savvy. Professors and industry practitioners are moderately aware because they are not practicing blockchain. At the same time, only professors who are teaching computer science and information technology are really interested in sharing their knowledge since this technology is so new.

The article also analyzed the many benefits of blockchain technology which make it favorable to educational institutions. It will serve as a foundational technology to enhance the record keeping techniques of academic institutions. It will also save the cost since printing expense is already eliminated and few manpower will be utilized, and, therefore, the quality of service will be improved. In addition, school credentials are available in real time which makes it unique. Finally, collaboration with other educational institutions will be easier and automatically generated.

\section{Recommendations}

Based on the findings and conclusions of the study, the following are hereby recommended: Blockchain will serve as a foundational technology, so the proponent recommends that students should focus and harness their skills of this innovative technology because many job opportunities will be available in the global market in the field of computing, both in hardware and software platforms. The same applies to industry practitioners.

It is recommended that professors should undertake further training in blockchain. Schools should include block chain technology in the faculty development program and partner with NEM Philippines "train the trainer program" for they provide blockchain technology seminar for free. 
The proponent recommends the adoption of EduChain by educational institution (if they have the capability in both hardware and software) because it will solve plenty of problems like the loss of credentials, delay in release of documents, and it is economical because it is paperless.

The researcher recommends EduChain Activity Process Flow to be adapted in higher education institutions because it will create a new paradigm in record management systems. A single user platform becomes a multi-user platform. Records are available in real time. Students have the option to share their records to potential employer. It is a secure way of keeping the records because data is encrypted.

The proponent recommends other uses of blockchain technology like e-learning, accreditation, e-portfolios, and the like because it will widen the reach plus the advantage of this technology.

Commission of Higher Education (CHED) may devise a policy about document preparations and enhanced security record keeping system.

Technical Skills and Development Authority (TESDA) may coordinate with other government agencies to include competencies acquired by skilled workers to showcase the skills they have gained.

Entrepreneurs can gain competitive advantage by partnering and collaborating with academic institutions regarding the use of blockchain technology.

The Department of Education (DepEd) may utilize blockchain technology in coordination with other government agencies to synchronize and systematize documentation of records.

Future researchers are recommended to further study blockchain on the improvement of recordkeeping techniques, including badges, paying with other currencies other than Ether, or developing another recordkeeping system based on other blockchain platforms.

The proponent also believes that this innovative technology will provide solutions to many issues and concerns brought about by traditional record keeping systems in all academic institutions not only in the Philippines, but globally.

\section{References}

[1] Alammary, A., Alhazmi, S., Almasri, \& M. Gillani, S. (2019). Blockchain-based applications in education: A systematic review. Applied Science. 9(12). 1-18.

https://doi.org/10.3390/app9122400

[2] Azogu, I., Norta, A., Papper, I., Longo, J. \& Draheim, D. (2019, April 3-5). A framework for the adoption of blockchain technology in healthcare information management system: A case study of Nigeria. [Conference paper]. ICEGOV'2019: The $12^{\text {th }}$ International Conference on Theory and Practice of Electronic Governance. Melbourne, Australia. doi:10.1145/3326365.3326405

[3] Briggs, S. (2018, January 18). Blockchain technology: Can it change education? InformED. https://www.opencolleges.edu.au/informed/edtech integration/blockchain-technologyeducation 
[4] Catalini, C. (2017, October 3). Why blockchain can be good for competition. Forbes. https://www.forbes.com/sites/christiancatalini/2017/10/30/why-blockchain-can-be-goodfor-competition/\#659a8dc4768e

[5] Chen, G., Xu, B., Lu, M., \& Chen, N. (2018, January 3). Exploring blockchain technology and its potential applications for education. Smart Learning Environment (5), Article 1. https://doi.org/10.1186/s40561-017-0050-X

[6] Durant, E., Trachy A. (2017, October 17). Digital diploma debuts at MIT. MIT News. https://news.mit.edu/2017/mit-debuts-secure-digital-diploma-using-bitcoin-blockchaintechnology-1017

[7] Fyrigou-Koulouri, M. (2018). Blockchain technology: An interconnected legal framework for an interconnected system. Journal of Law, Technology \& the Internet, 9(1), 1-14. https://scholarlycommons.law.case.edu/jolti/vol9/iss1/7/

[8] Impact Chain Lab. (2017, December 8). 4 ways blockchain could change the education system. Medium. https://medium.com/@impactchainlab/4-ways-blockchain-couldchange-the-education-system-988fc7c3db42

[9] Jenkinson, G. (2019, October 15). Blockchain and the classroom - how DLT can improve education. https://cointelegraph.com/news/blockchain-and-the-classroom-how-dlt-canimprove-education.

[10] Jirgensons, M. and Kapenieks, J. (2018). Blockchain and the future of digital learning credential assessment and management. Journal of Teacher Education for Sustainability, 20(1), 145-156, 2018. doi:10.2478/jtes-2018-0009.

[11] Limieux, V. L. (2016, October). Blockchain for recordkeeping: Help or hype? (Vol. 1). [Technical report]. ResearchGate. DOI: 10.13140/RG.2.2.21736.67842

[12] McArthur, D. (2018). Will blockchain revolutionize education? EDUCAUSE. 1-15. https://er.educause.edu/articles/2018/5/will-blockchains-revolutionize-education

[13] Mittal, A. (2018). Blockchain technology in education. C\# Corner. https://www.csharpcorner.com/article/blockchain-in-education-technology/

[14] Mirzamany, E. \& Hanif, M. (2018). Blockchain: An enabler of efficiency, choice and agility in education. Jisc. https://community.jisc.ac.uk/sites/default/files/BlockchainEducation.pdf $\backslash$

[15] El Nokiti, A. \& Yusof, S. (2019). Exploring the perceptions of applying blockchain technology in the higher education institutes in the UAE. Proceedings, 28(8). 1-11. doi:10.3390/proceedings2019028008

[16] Raval, S. (2018). What role education is playing in the education sector? Bacancy Technology. https://www.bacancytechnology.com/blog/blockchain-in-education-sector

[17] Ray, T. (2018). Scope of blockchain technology in the college admission process. Stoodnt. https://www.stoodnt.com/blog/blockchain-in-college-admissions/ 
[18] Riddell, R. (2017, August 7). Will blockchain change the face of K-12 record storage and tracking? Education Drive. https://www.educationdive.com/news/blockchain-k12-recordstorage-and-tracking/448698/

[19] Riksen, D. (2017). Blockchain in Education 2017: An inspiring 'tour d'horizon'. Groningen, Denmark.

[20] Shilov, K. (2018, July 10). What type of blockchain would be better for educational tasks. Hackernoon. https://hackernoon.com/what-type-of-blockchain-would-be-better-foreducational-tasks-a203dde826c3

[21] Silva, E. (2019, October 1). How can blockchain help your business gain a competitive advantage? Your Story. https://yourstory.com/mystory/how-blockchain-helps-incompetitive-advantage

[22] Sultan, K., Ruhi, U., \& Lakhani, R. (2018). Conceptualizing blockchains: Characteristics and applications [Conference paper]. $11^{\text {th }}$ IADIS International Conference Information Systems. University of Ottawa, Canada.

[23] Tapscott, D. \& Tapscott, A. (2017, March 13). The blockchain revolution and higher education. EDUCAUSE Review. https://er.educause.edu/articles/2017/3/the-blockchainrevolution-and-higher-education

[24] Ark, T. (2018, August 20). 20 ways blockchain will transform (Okay, may improve) education. Forbes. https://www.forbes.com/sites/tomvanderark/2018/08/20/26-waysblockchain-will-transform-ok-may-improve-education/\#4c6a52614ac9 